\title{
ASSORTATIVE FERTILIZATION AND SELECTION AT LARVAL STAGE IN THE MUSSELS MYTILUS EDULIS AND M. GALLOPROVINCIALIS
}

\author{
Nicolas Bierne, ${ }^{1,2}$ Patrice David, ${ }^{3,4}$ Pierre Boudry, ${ }^{5,6}$ and François Bonhomme ${ }^{1,7}$ \\ 'Laboratoire Génome, Populations, Interactions, Centre National de la Recherche Scientifique-UMR5000, \\ Station Méditerranéenne de l'Environment Littoral, 34200 Sète, France \\ ${ }^{2}$ E-mail: n-bierne@univ-montp2.fr \\ ${ }^{3}$ Centre National de la Recherche Scientifique-Centre d'Ecologie Fonctionelle et Evolutive, 34293 Montpellier Cedex 5, France \\ ${ }^{4}$ E-mail: pdavid@cefe.cnrs-mop.fr \\ ${ }^{5}$ Laboratoire de Génétique et Pathologie, Institut Français de Recherche pour l'Exploitation de la mer, \\ I7390 La Tremblade, France \\ ${ }^{6}$ E-mail: Pierre.Boudry@ifremer.fr \\ ${ }^{7}$ E-mail: bonhomme@univ-montp2.fr
}

\begin{abstract}
Assortative mating (prezygotic isolation) and reduced hybrid fitness (postzygotic isolation) are typically invoked to explain the stability of hybrid zones. In the tension zone model, these factors work in opposition to migration, which promotes genetic homogeneity. Many marine animals migrate over long distances through a planktonic larval stage. Therefore, strong reproductive isolation is needed to maintain stable marine hybrid zones. However, surprisingly little is known about mating preferences and hybrid fitness in marine organisms. Smooth-shelled mussels (Mytilus spp.) form a well-known species complex, with hybridization over extensive areas such as the contact zone of $M$. edulis and $M$. galloprovincialis around European Atlantic coasts. This paper reports direct experimental evidence of assortative fertilization, hybrid larval inviability, and early heterosis for growth rate in $M$. edulis and $M$. galloprovincialis. Four crosses between pure $M$. edulis and $M$. galloprovincialis were analyzed with a new polymerasechain-reaction-based diagnostic marker. Gamete competition between taxa was allowed in two out of the four crosses. Genotype frequencies observed at an early stage ( $36 \mathrm{~h}$ after fertilization) unambiguously revealed assortative fertilization when gamete competition was allowed. A significant reduction in hybrid viability was subsequently observed during the larval stage. At the same stage an antagonistic effect, heterosis, was observed on growth rate. However, even if heterosis is observed in the $F_{1}$, it is expected to vanish in subsequent hybrid generations. Although specialization for different habitats and asynchronous spawning have been mentioned as factors contributing to the maintenance of the blue mussel hybrid zone in Europe, we argue that assortative fertilization and reduced hybrid fitness are important factors that also contribute to the stabilization of this zone. These results emphasize that multiple factors may act concomitantly in a barrier to gene flow, especially in complex life cycles. Furthermore, they show that assortative mating through gamete preference, as already demonstrated for sea urchins, may play a role in speciation processes taking place in the sea.
\end{abstract}

Key words. - Gamete competition, heterosis, hybrid viability, Mytilus edulis, Mytilus galloprovincialis, preferential fertilization.

Received May 15, 2001. Accepted October 16, 2001.

Hybridization is not an uncommon phenomenon in marine organisms (Gardner 1997). However, empirical and theoretical studies on hybrid zones have focused mainly on terrestrial species (reviewed by Barton and Hewitt 1985, 1989; Harrison 1993; Arnold 1997). Exogenous and endogenous factors involved in preventing genomes of two species from merging depend on the life cycle. In most marine bivalves, this cycle is characterized by a sessile adult phase, high fecundity, external fertilization, and extensive larval dispersal, which provide extensive gene flow that should prevent geographic isolation and the potential for strong selection in an often unpredictable environment. Therefore, it is perhaps not surprising that one of the best-known marine hybrid zones, between the mussels Mytilus edulis and $M$. galloprovincialis in European Atlantic coasts, has revealed an unusual complexity. This zone shows a considerable extension, from the southwest of France to Scottish coasts (Skibinski et al. 1978, 1983; Coustau et al. 1991a) and has a mosaic structure, in which populations of pure genotypes alternate with hybrid populations (Skibinski et al. 1983; Daguin et al. 2001). Spatial distribution of alleles suggests the influence of environmental factors such as salinity (Skibinski 1983) and wave exposure or tidal height (Gosling and Wilkins 1981; Gardner and Skibinski 1988; Gosling and McGrath 1990; reviewed in Gardner 1994). Depending on location, hybrid populations display highly variable levels of introgression, from complete introgression (intermediate allele frequencies and HardyWeinberg plus linkage equilibrium, HWLE) to simple admixture (superposition of two parental populations; Skibinski et al. 1983; Daguin et al. 2001). Thus, despite extensive hybridization, there still remain two incompletely blended genetic entities, implying some barrier to gene flow. Habitat specialization and, although less studied, asynchronous spawning have been shown to be involved in this barrier (Gardner 1994). How these two mechanisms act exactly is not yet well understood, and it is not known whether they alone can explain the hybrid zone structure and stability observed. Other mechanisms such as gamete recognition and fertilization preference could be implicated (Arnold 1997).

Even though cellular mechanisms have been extensively examined between well-separated marine species (review in Palumbi 1992, 1994), experimental evidence from naturally occurring marine hybrid zones is lacking, although this is an important issue in the understanding of mechanisms that actually have a bearing on the speciation process. In the case of $M$. edulis and $M$. galloprovincialis, experimental crosses 
as well as genetic analyses of natural populations have demonstrated the existence of cross-fertilization (Gardner 1994), but we are not aware of any test of gamete preference. In any case, these mechanisms alone do not suffice to explain the long-term maintenance of separate gene pools once hybrids are produced in visible numbers. There has to be some sort of lower fitness of hybrids at the postzygotic stage (Barton and Hewitt 1989). This is why the evaluation of relative fitness parameters among parental and hybrid genotypes is a keystone in the study of hybrid zones (Barton and Hewitt 1989). The Mytilus hybrid zone in Europe has mainly been investigated using genotype-phenotype associations in adult natural populations (Coustau et al. $1991 \mathrm{~b}$; Gardner and Skibinski 1991; Gardner et al. 1993; Gardner 1994; Hilbish et al. 1994). These analyses concluded that $M$. galloprovincialis genotypes have an advantage over both hybrids and $M$. edulis genotypes for growth, fecundity, strength of attachment, and viability (Gardner and Skibinski 1990, 1991; Gardner 1994). However, such studies pose the problem of whether two allozyme loci are sufficient to represent the degree of mixing in the whole genome. Surprisingly, few studies of experimental crosses have been conducted. We were able to find only two such studies in the literature (Lubet et al. 1984; Beaumont et al. 1993). Lubet et al. (1984) did not find any differential viability or growth between parental and $F_{1}$ categories at the adult stage, whereas results in Beaumont et al. (1993) suggested reduced hybrid viability during the early larval stage.

The aims of the present study were to investigate the effect of gamete competition on cross-fertilization success and the relative survival and growth rate of parental and $F_{1}$ individuals from controlled crosses at different stages of the life cycle in the mussels $M$. edulis and $M$. galloprovincialis. We focused on early stages of the life cycle (larval stage, metamorphosis) during which most of the developmental processes and mortality take place and which remain largely unexplored. In this type of study, different genotypes are usually kept separate in different tanks (e.g., Beaumont et al. 1993). In our experiment, however, all progeny were reared in the same tank and genotypes were subsequently deduced from molecular marker analyses. This approach has several advantages: (1) environmental variation is erased; (2) interaction between genotypes, such as competition, is allowed; and (3) the effects of gamete competition can be investigated by comparing genotypic composition just after fertilization between crosses in which competition is allowed and crosses in which it is not (Huvet et al. 2001). We also present a new marker named EFbis, diagnostic between the M. edulis and M. galloprovincialis used in the crosses, which was obtained by the exon-primed intron-crossing polymerase chain reaction (EPIC-PCR) method (Palumbi 1995; Bierne et al. 2000) in the first intron of the elongation factor $1 \alpha$ gene (Regier and Shultz 1998).

\section{Materials and Methods}

\section{Crosses}

Mytilus edulis adults were collected from two North Sea populations, at Grand-Fort-Philippe (GFP, France) and in a population from Holland (HOL). Mytilus galloprovincialis adults were collected from two populations at Sète (SET) on the French Mediterranean coast and at Vigo (VIG) in Galicia on the Atlantic coast of Spain. Temperature of maturation was controlled in the laboratory in closed-circuit tanks (around $24^{\circ} \mathrm{C}$ for $M$. galloprovincialis and around $18^{\circ} \mathrm{C}$ for $M$. edulis). Maturity was regularly checked by inducing spawning of a few individuals by a thermal shock (Lubet et al. 1984). Temperature and feeding were adjusted to synchronize maturation among species. Mytilus galloprovincialis reached full maturation slightly earlier than $M$. edulis. In December 1998, all the adults were individually induced to spawn. Four female $M$. edulis spawned, two from GFP and two from HOL, so we decided to equalize the crossing scheme by choosing four $M$. edulis males (two from GFP and two from HOL), four $M$. galloprovincialis females (two from SET and two from VIG), and four M. galloprovincialis males (two from SET and two from VIG). Oocytes were gently sieved, counted using Mallassez slides, and adjusted to $10^{6}$ per female. Spermatozoa were treated in the same manner using Thoma slides and adjusted to $10^{8}$ per male to obtain a 100 : 1 sperm:egg ratio for the fertilization.

Two kinds of treatments were performed, by pooling either gametes (GP) or embryos (EP). For a GP cross, fertilization occurred within a mix of oocytes from all the females and a mix of spermatozoa from all the males. In this kind of cross, among-species gamete competition was allowed. For an EP cross, the following crosses were made in four different beakers: $M$. edulis oocytes x $M$. edulis sperm, $M$. edulis oocytes x $M$. galloprovincialis sperm, $M$. galloprovincialis oocytes $\mathrm{x}$ $M$. edulis sperm, and $M$. galloprovincialis oocytes x $M$. galloprovincialis sperm. Four hours after fertilization, embryos resulting from these four crosses were mixed together. Two replicates of the GP: GP1 and GP2, and of the EP: EP1 and EP2, were produced.

\section{Collection and Treatment of Larvae}

For each trial, larvae were transferred into a $30-\mathrm{L}$ cylindrical larval growing pond (initial larval density $=10$ larvae $\mathrm{ml}^{-1}$ ). Sea water at $18^{\circ} \mathrm{C}$, filtered at $0.2 \mu \mathrm{m}$, was changed every two days. Larvae were fed with Pavlova lutheri and Chaetoceros calcitrans every day. Thirty-five days after fertilization larvae were undergoing metamorphosis and were transferred in a 20 -L closed-circuit tanks for five days. A coconut rope was placed in each tank to encourage fixation. The circuit was then opened to a continuous water flow, sieved at $200 \mu \mathrm{m}$ to prevent contamination by local larvae (even though this was highly improbable during the season of the experiment), and kept at $18^{\circ} \mathrm{C}$. Samples were taken 36 $\mathrm{h}$ after fertilization, at the end of the larval stage (day 35) before settlement, and at the juvenile stage (day 100). Unfortunately, all the individuals in EP2 died for an unknown reason between day 35 and day 100 . Individualization of larvae as well as DNA extraction was performed as described in Bierne et al. (1998).

\section{Molecular Marker}

Intron-spanning primers were designed in the elongation factor $1 \alpha$ cDNA sequences (Regier and Shultz 1998) as described in Bierne et al. (2000) and references therein. Prim- 


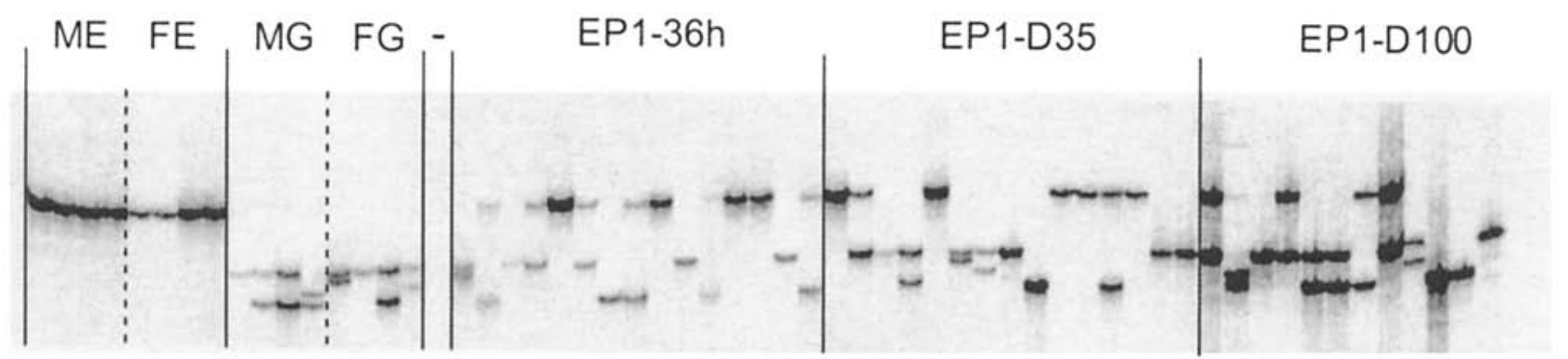

FIG. 1. Intron length polymorphism obtained at the EFbis locus. First 16 lanes: parents used in the experiment. ME, Mytilus edulis males; FE, $M$. edulis females ( $M$. edulis parents are homozygous $\mathrm{EE}$ ); $\mathrm{MG}, M$. galloprovincialis males (genotypes: $\mathrm{G}_{3} \mathrm{G}_{3}, \mathrm{G}_{0} \mathrm{G}_{3}, \mathrm{G}_{0} \mathrm{G}_{3}$, $\mathrm{G}_{0} \mathrm{G}_{1}$ ); FG, $M$. galloprovincialis females (genotypes: $\mathrm{G}_{2} \mathrm{G}_{3}, \mathrm{G}_{3} \mathrm{G}_{3}, \mathrm{G}_{0} \mathrm{G}_{3}, \mathrm{G}_{1} \mathrm{G}_{3}$ ). Lane 17: negative polymerase chain reaction control. EP1-36h: 15 36-h-old larvae from sample EP1-36h; EP1-D35: 15 35-day-old larvae from sample EP1-D35; EP1-D100: 12 100-day-old juveniks from sample EP1-D100.

er sequences are EFbis-F: 5'-ACAAGATGGACAATAC CGAACCACC-3' and EFbis-R: $5^{\prime}$-CTCAATCATGTTGT CTCCATGCC-3' ${ }^{\prime}$. We used the PCR and electrophoresis procedures described in Daguin and Borsa (1999), except that annealing temperature was set to $54^{\circ} \mathrm{C}$. The EFbis locus exhibited length polymorphism that appeared to be diagnostic between the $M$. edulis and $M$. galloprovincialis used in the present experiment (see Fig. 1).

\section{Statistical Analyses}

The four $M$. galloprovincialis alleles $\left(\mathrm{G}_{0}, \mathrm{G}_{1}, \mathrm{G}_{2}, \mathrm{G}_{3}\right)$ were pooled as a single synthetic allele, $G$, for the analysis. Genotypes were: $M$. edulis (EE), $\mathrm{F}_{1}$ hybrid (EG), and $M$. galloprovincialis (GG). Random mating was tested for the 36 h samples using the Hardy-Weinberg exact test in the GENEPOP software (Raymond and Rousset 1995). Deviations from the expected heterozygote frequencies were estimated as $D$ $=\left(H_{\mathrm{obs}} / H_{\text {exp }}\right)-1$, where $H_{\mathrm{obs}}$ is the number of observed heterozygotes and $H_{\text {exp }}$ the number of expected heterozygotes under Hardy-Weinberg equilibrium (HWE). Homogeneity of genotypic frequencies was tested within crosses among time samples and between crosses within each sampling time using Fisher's exact test in the GENEPOP software. Differences in growth rates among genotypes were tested using a one-way ANOVA with fixed effect.

Heterosis can be quantified as $h_{\mathrm{p}}=Q / L$, where $L$ is the trait difference between the two parental lines and $Q$ is twice the deviation of the hybrid from the midparent value (Griffing 1990; Hedgecock et al. 1995). It is a useful synthetic coefficient that allows the hybrid to be easily compared with the parental phenotypic values: $h_{\mathrm{p}}>1$ means heterosis, $h_{\mathrm{p}}<-1$

TABLE 1. Allele and genotype frequencies and heterozygote deficits $(D)$ at $36 \mathrm{~h}$ for crosses in which gamete competition is allowed (GP) and crosses in which it is not (EP). EE, Mytilus edulis; EG, $\mathrm{F}_{1}$ hybrids; $\mathrm{GG}, M$. galloprovincialis; $n$, sample size.

\begin{tabular}{|c|c|c|c|c|c|c|}
\hline & \multicolumn{2}{|c|}{$\begin{array}{c}\text { Allele } \\
\text { frequencies }\end{array}$} & \multicolumn{3}{|c|}{$\begin{array}{l}\text { Genotype } \\
\text { frequencies }\end{array}$} & \multirow[b]{2}{*}{$D$} \\
\hline & $\mathrm{E}$ & G & $\mathrm{EE}$ & EG & GG & \\
\hline GP-36h $(n=116)$ & 0.23 & 0.77 & 0.11 & 0.23 & 0.66 & $-0.34 * * *$ \\
\hline EP-36h $(n=180)$ & 0.42 & 0.58 & 0.18 & 0.48 & 0.34 & -0.02 \\
\hline
\end{tabular}

*** $P<0.001$. means hybrid depression and $-1<h_{\mathrm{p}}<1$ means that hybrids are intermediate.

\section{RESULTS}

\section{Effect of Gamete Competition at 36 Hours}

No significant difference in genotype frequencies was observed between GP1 and GP2 or between EP1 and EP2 at 36 h. Data were thus pooled among GPs and EPs. Results are synthesized in Table 1. Estimated abortion rates, quantified by comparing the number of oocytes used and the number of larvae obtained at $36 \mathrm{~h}$ were $18 \%$ in GP and $12 \%$ in EP. Allele frequencies at $36 \mathrm{~h}$ departed significantly from equal species contribution (EP: $P=0.017$; GP: $P<0.001$ ) and genotype frequencies were significantly different between GP and EP $(P<0.001)$. This was partly due to a lower contribution of the $M$. edulis allele, E, especially when gametic competition was allowed (EP: $\mathrm{E}=0.42 ; \mathrm{GP}: \mathrm{E}=0.23$ ). Another source of differences between GP and EP was that genotypic frequencies strongly departed from $\mathrm{HWE}$ in GP $(P<0.001)$, whereas no departure was observed in EP.

The aim of this experiment was first to test for random mating when gamete competition was allowed (GP). Clearly this was not the case, because a significant heterozygote deficiency was observed in this cross when compared to the expectation under HWE. The interpretation of this result is complicated because, despite our standardization, we do not know whether the effective contribution of each species was the same in eggs and sperm. Equal frequencies between sexes are a necessary condition for HWE. However, unequal frequencies generate an excess of heterozygotes under random mating. Using the observed frequencies in GP crosses (e.g., $\mathrm{E}=0.23$ and $\mathrm{EE}=0.11$ ), one can deduce that the effective frequency of the $M$. edulis oocytes in this cross, $\mathrm{E}_{\mathrm{f}}$, was 0.11 $<\mathrm{E}_{\mathrm{f}}<0.35$. The predicted heterozygote excess therefore lies between 0.00 (sperm and egg frequencies both equal to 0.23 ) and 0.08 (frequency equal to 0.11 in one sex and 0.35 in the other). The observed value of $D=-0.34$ clearly means that there are less hybrids than expected under random mating.

\section{Differential Viability}

No significant difference in genotype frequencies was observed between GP1 and GP2 within the same sampling times 

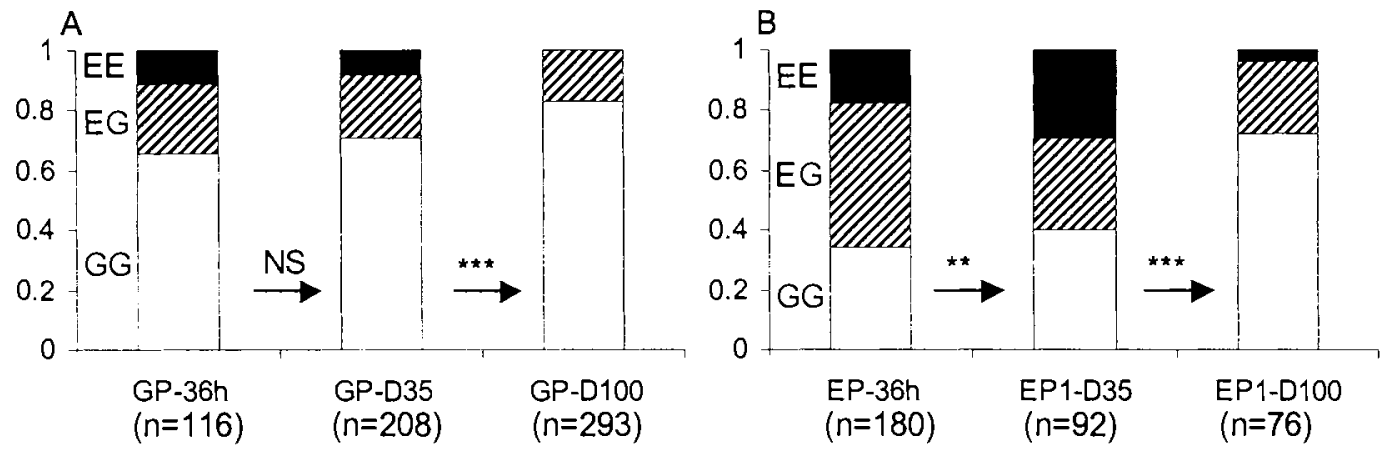

FIG. 2. Genotype frequencies at the EFbis locus for different sampling times: (A) crosses in which gamete competition was allowed (GP); and (B) crosses in which gamete competition was prevented (EP). EE, Mytilus edulis; EG, $\mathrm{F}_{1}$ hybrids; GG, M. galloprovincialis; $n$, sample size.

(data not shown), and data were pooled. Genotypic frequencies are presented in Figure 2A. A significant difference in genotypic frequencies was observed between day 35 and day $100(P<0.001)$. EP1 and EP2 exhibited significant differences in genotypic frequencies at day $35(P=0.04)$ and data were not subsequently pooled. Figure $2 \mathrm{~B}$ depicts the EP1 genotypic frequencies at day 35 and day 100. EP2 is not represented, because all individuals of this group were lost between day 35 and day 100 . EP2 genotype frequencies at day 35 were $\mathrm{EE}=0.15, \mathrm{EG}=0.28$, and $\mathrm{GG}=0.57(n=$ 92). A significant difference in genotype frequencies was observed between $36 \mathrm{~h}$ and day 35 for EP1 $(P=0.01)$ and EP2 $(P=0.014)$ and between day 35 and day 100 for EP1 $(P<0.001)$. Table 2 summarizes the relative viability normalized by the fittest genotype and the corresponding heterosis coefficient, $h_{\mathrm{p}}$. On the whole, M. galloprovincialis exhibited the best viability, there was strong selection against $M$. edulis genotypes, and hybrids were intermediate as shown by $-1<h_{\mathrm{p}}<1$. Interestingly, in EP crosses, hybrid depression was detected during the larval stage (EP1: $h_{\mathrm{p}}=-3$, EP2: $h_{\mathrm{p}}=-1.6$ ), although a strong subsequent selection against $M$. edulis during the settlement process did restore a slightly less negative $h_{\mathrm{p}}(=-0.8)$.

\section{Differential Growth}

Table 3 presents the mean shell length and the 95\% confidence interval for each genotype and heterosis coefficients in each trial at the pediveliger stage (day 35) and the spat stage (day 100 ). $F_{1}$ hybrids were significantly larger than parental genotypes in two out of the four trials (GP1: $F=$ $0.07, \mathrm{df}=107, P=0.9 ; \mathrm{GP} 2: F=2.2, \mathrm{df}=99, P=0.11$; EP1: $F=3.4, \mathrm{df}=91, P=0.03 ; \mathrm{EP} 2: F=6.7, \mathrm{df}=91$, $P=0.002)$ and overall $(P=0.002)$ using Fisher's method to combine independent tests (Sokal and Rohlf 1996). An opposite trend was thus observed for larval growth rate to that for larval viability. After metamorphosis (day 100), $F_{1}$ hybrids became smaller than $M$. galloprovincialis (Table 3, the comparison with $M$. edulis was impossible because of strong mortality for this genotype). This was significant in one out of three trials (GP1: $F=0.24$, df $=156, P=0.6$; GP2: $F=0.4, \mathrm{df}=135, P=0.5 ; \mathrm{EP} 1: F=5.9, \mathrm{df}=75$, $P=0.015)$.

\section{Discussion}

Mechanisms known to be involved in gamete recognition among marine organisms have been examined (Palumbi 1994), and some molecules implicated in the egg-sperm interaction identified (Vacquier and Moy 1977; Ward et al. 1985; Vacquier et al. 1990). Interactions can take place at various stages from gamete release to fertilization (Garbers 1989), and it is not always possible to distinguish among specific spawning induction, gamete attraction, or fertilization processes. Analyses may be further complicated by early developmental failure. If certain mechanisms are now well known, it is also true that few studies have examined fertilization patterns between closely related marine species ( $\mathrm{Pal}-$ umbi 1994). Furthermore, these patterns have been almost exclusively considered in the absence of gamete competition, although assortative fertilization has been recently demonstrated in the sea urchin Echinometra mathaei (Palumbi 1999). Before using our results to assess assortative fertilization and hybrid fitness in Mytilus species, we will discuss the unequal gamete contributions of the two species in our experiment.

TABLE 2. Relative viability normalized by the fittest genotype and heterosis coefficient, $h_{\mathrm{p}}$, during the larval stage (36 $\mathrm{h}$ to day 35 ) and globally (36 h to day 100). EE, Mytilus edulis; EG, $\mathrm{F}_{1}$ hybrids; GG, M. galloprovincialis. Sample sizes as in Figure 2.

\begin{tabular}{|c|c|c|c|c|c|c|c|c|c|}
\hline & \multicolumn{3}{|c|}{ GP } & \multicolumn{3}{|c|}{ EP1 } & \multicolumn{3}{|c|}{ EP2 } \\
\hline & $\mathrm{EE}$ & $\mathrm{EG}$ & $\mathrm{GG}$ & $\mathrm{EE}$ & $\overrightarrow{E G}$ & $\mathrm{GG}$ & $\mathrm{EE}$ & $\mathrm{EG}$ & GG \\
\hline Larval stage & 0.6 & $\begin{array}{l}0.9 \\
h=0.2\end{array}$ & 1 & 1 & $\begin{array}{c}0.4 \\
h=-3.0\end{array}$ & 0.7 & 0.5 & $\begin{array}{c}0.4 \\
h=-1.6\end{array}$ & 1 \\
\hline
\end{tabular}


TABLE 3. Mean shell length and $95 \%$ confidence interval at two sampling times (day 35 shell length [ $\mu \mathrm{m}$ ] and day 100 shell length [mm]) and heterosis coefficient, $h_{\mathrm{p}}$, at day 35 . EE, Mytilus edulis; EG, $\mathrm{F}_{1}$ hybrids; GG, M. galloprovincialis. Sample sizes as in Figure 2.

\begin{tabular}{|c|c|c|c|c|c|}
\hline & \multicolumn{3}{|c|}{ Day 35} & \multicolumn{2}{|c|}{ Day 100} \\
\hline GPI & $281 \pm 12$ & $\begin{aligned} 280 & \pm 21 \\
h_{\mathrm{p}} & =0.8\end{aligned}$ & $271 \pm 13$ & $1.98 \pm 0.17$ & $2.02 \pm 0.06$ \\
\hline GP2 & $256 \pm 7$ & $\begin{aligned} 271 & \pm 11 \\
h_{\mathrm{p}} & =4.0\end{aligned}$ & $262 \pm 13$ & $1.7 \pm 0.15$ & $1.75 \pm 0.07$ \\
\hline $\mathrm{EPl}$ & $257 \pm 8$ & $\begin{aligned} 273 & \pm 9 \\
h_{\mathrm{p}} & =7.0\end{aligned}$ & $261 \pm 10$ & $2.16 \pm 0.2$ & $2.45 \pm 0.12$ \\
\hline
\end{tabular}

\section{Unequal Gametic Contributions of the Two Species}

In such an experiment, it is nearly impossible to obtain equal parental contributions. Even if it were possible to adjust parents to a precise 1:1 ratio, there is no way to standardize gamete quality among parents. The realized effective gamete ratio is thus expected to be distorted and must be estimated a posteriori from the data. It is therefore not surprising to obtain a significant departure from equal species contribution. $G$ alleles may be overrepresented either because errors in gamete counts have favored $M$. galloprovincialis by chance or because $M$. galloprovincialis gametes were more efficient or more viable. Differential early abortions may also be involved. The fact that the excess of $G$ alleles is larger in GP than in EP crosses can be attributed either to a severe error in sperm counts (this should affect GP crosses but not EP crosses, in which the two sperm types are not in competition) or an enhanced effect of differences in sperm quality by gamete competition (Boudry et al. 2002). Because we suspect that $M$. edulis parents were less mature than $M$. galloprovincialis parents, we favor the hypothesis of better quality of M. galloprovincialis gametes.

\section{Assortative Fertilization}

The heterozygote deficiency obtained in the GP cross may be explained either by (1) assortative fertilization (gamete choice); or (2) differential fertilization (fertilization failure) or abortion. The lack of heterozygote deficiency in the EP cross favors the first hypothesis because differential fertilization or abortion should have occurred both in EP and GP crosses, although gamete choice was only possible in GP. Moreover, abortion percentages seem insufficient to generate the observed heterozygote deficiency in GP. Indeed, in the worst case, if we hypothesize that all the $18 \%$ aborted embryos in GP were hybrids, the heterozygote deficiency would reach the value of $D \approx-0.08$. Assortative fertilization must therefore have occurred in GP. In conclusion, when there is no other choice (EP cross), cross-fertilization occurs without much problem, whereas when choice is possible (GP) intraspecific fertilization is preferred.

Our experiment does not provide a direct demonstration of the asymmetry of the fertilization barrier (i.e., whether crosses between male $M$. galloprovincialis and female $M$. edulis are easier than the reverse). However, our results suggest asymmetry. As shown in the results section, the effective frequency of the $M$. edulis oocytes in GP crosses was 0.11
$<E_{\mathrm{f}}<0.35$. We can use EP crosses to estimate the value of $E_{f}$. Both crosses are subject to equal counting biases (because the same gamete solutions were split among the two crosses). The $\mathrm{E}$ frequency in the EP experiment (representative of the maximum count bias) was 0.42 . Assuming, conservatively, that the $18 \%$ abortion in GP only affected embryos derived from $\mathrm{E}$ oocytes (initially in frequency 0.42 ), the minimal frequency of $E$ in fertilized oocytes would be $\mathrm{E}_{\mathrm{f}} \approx 0.30$, which is in the upper range of possible values (0.11-0.35). The effective contribution of $M$. edulis males was therefore close to its minimum value $(0.11)$. Thus, almost all M. edulis sperm might have been employed in conspecific fertilization, whereas hybrids might be virtually exclusively the product of $M$. edulis oocytes with $M$. galloprovincialis sperm. This observation calls for additional experiments with gamete ratio manipulation.

\section{Hybrid Fitness}

The overall viabilities from the embryo to the spat stage (day 100) seem to reflect directional selection favoring $M$. galloprovincialis genotypes. However, this is no longer true when the two different phases (the larval phase from embryo to pediveliger and metamorphosis from pediveliger to spat) are considered separately. During the larval phase, no significant viability differences were observed in GP crosses, whereas a significant depression for hybrid larval viability was observed in EP crosses (EP1: $h_{\mathrm{p}}=-3, P=0.008$; EP2: $\left.h_{\mathrm{p}}=-1.6, P=0.015\right)$. We confirm the results obtained by Beaumont et al. (1993) that hybrid depression for larval viability occurs between M. edulis and M. galloprovincialis, but we did not detect such depression in the GP crosses. However, the power to detect inviability was lower in GP crosses because of the imbalance among different types of embryos right from the beginning. Furthermore, in the EP crosses, both categories of hybrids (male $G \times$ female $E$ or the reverse) are present in approximately equal frequencies, whereas most hybrids in the GP crosses are suspected to be of the male G $\times$ female $E$ type. If both categories of hybrids have different viabilities, this may explain the differences between EP and GP. Results in Beaumont et al. (1993) also suggested that this might be the case as male $G \times$ female $E$ hybrids had always exhibited a better viability than the reverse type in their experiment. Reduced $F_{1}$ viability is not a predictable outcome in interspecific hybrids, although it is not uncommon (Barton and Hewitt 1985). It is much more frequent in suc- 
cessive backcross or $F_{2}$ generations because of gene coadaptation breakup (Edmands 1999). Despite inferior viability, hybrid veligers exhibited an increased growth rate (mean $h_{\mathrm{p}}$ $=3.8, P=0.002$ ), confirming the heterosis for larval growth rate suggested by Beaumont et al. (1993). Heterosis is usually expected for $\mathrm{F}_{1}$ progeny because hybrid dysgenesis only appears in subsequent generations of hybridization. Indeed, it has long been recognized that interspecific hybrids, although often sterile, show increased vigor and growth (a phenomenon called "luxuriance"' by Dobzhansky 1952).

Tendencies observed during the larval stage were reversed during metamorphosis and early spat stages. A strong selection against $M$. edulis genotypes restored an intermediate $h_{\mathrm{p}}$ for viability, and $\mathrm{F}_{1}$ hybrids were smaller than $M$. galloprovincialis spat.

A general caveat on results such as ours is the influence of environment. Our rearing facilities are on the Mediterranean sea in a region where the environment should be favorable to $M$. galloprovincialis. Because genotype-by-environment interactions may be important, such experiments should be replicated in a gradient of environmental conditions. However, we are left with the fact that hybrids are less viable than either parent during the larval phase, which shows that, at least in some environmental conditions, selection is not simply directional.

\section{Implications for Stability of the Hybrid Zone}

Selection against hybrids is the most frequent explanation proposed for hybrid zone stability and is probably the most widespread (Barton and Hewitt 1989), although it may act in conjunction with other mechanisms (Arnold 1997). In the case of the $M$. edulis and $M$. galloprovincialis hybrid zone, habitat specialization or asynchronous spawning have been identified as barriers to gene flow (Gardner 1994), but alone they seemed to be insufficient to explain the intensity of the barrier, given the extensive hybridizations observed. Our results suggest two new isolation mechanisms that may have been overlooked previously because the larval phase was not studied. First, partial postzygotic isolation can proceed from a reduced hybrid fitness during the larval stage. Second, partial prezygotic isolation is observed when competition is possible (which is probably the case in natural mussel beds), providing another example of what may be an important contribution to speciation mechanisms in marine invertebrates.

\section{ACKNOWLEDGMENTS}

We are very much indebted to A. Mordacque for participating in laboratory analyses; Mr. and Mrs. Lemaire for arranging in the collection of the GFP sample; P. Borsa, C. Daguin, B. Godelle, A. Huvet, and M. Valero for helpful discussions; and H. McCombie for her comments on the manuscript. Two anonymous referees provided insightful remarks on the manuscript. We also thank A. Duday and P. Phélipot for some advice on mussel rearing. This research was funded in part by IFREMER URM 16.

\section{Literature Cited}

Arnold, M. L. 1997. Natural hybridization and evolution. Oxford Univ. Press, New York.
Barton, N. H., and G. M. Hewitt. 1985. Analysis of hybrid zones. Annu. Rev. Ecol. Syst. 16:113-148.

- 1989. Adaptation, speciation and hybrid zones. Nature 341 : 497-503.

Beaumont, A. R., A. K. M. Abdul-Matin, and R. Seed. 1993. Early development, survival and growth in pure and hybrid larvae of Mytilus edulis and $M$. galloprovincialis. J. Molluscan Stud. 59: $120-123$.

Bierne, N., S. Launey, Y. Naciri-Graven, and F. Bonhomme. 1998 Early effect of inbreeding as revealed by microsatellite analyses on Ostrea edulis larvae. Genetics 148:1893-1906.

Bierne, N., S. A. Lehnert, E. Bedier, F. Bonhomme, and S. S. Moore. 2000. Screening for intron-length polymorphisms in penaeid shrimps using exon-primed intron-crossing (EPIC)-PCR. Mol. Ecol. 9:233-235

Boudry, P., B. Collet, F. Cornette, V. Hervouet, and F. Bonhomme. 2002. High variance in reproductive success of the Pacific oyster (Crassostrea gigas, Thunberg) revealed by microsatellite-based parentage analysis of multifactorial crosses. Aquaculture. In press.

Coustau, C., F. Renaud, and B. Delay. 1991a. Genetic characterization of the hybridization between Mytilus edulis and M. galloprovincialis on the Atlantic coast of France. Mar. Biol. 111: 87-93.

Coustau, C., F. Renaud, C. Maillard, N. Pasteur, and B. Delay. 199 lb. Differential susceptibility to a trematode parasite among genotypes of the Mytilus edulis/galloprovincialis complex. Genet. Res. Camb. 57:207-212.

Daguin, C., and P. Borsa. 1999. Genetic characterisation of Mytilus galloprovincialis Lmk. in North West Africa using nuclear DNA markers. J. Exp. Mar. Biol. Ecol. 235:55-65.

Daguin, C., F. Bonhomme, and P. Borsa. 2001. Mosaicism in the European zone of sympatry and hybridization of Mytilus edulis and $M$. galloprovincialis, as revealed by intron length polymorphism at locus mac- 1 . Heredity 86:342-354.

Dobzhansky, T. 1952. Nature and origin of heterosis. Iowa State College Press, Ames, IA

Edmands, S. 1999. Heterosis and outbreeding depression in interpopulation crosses spanning a wide range of divergence. Evolution 53:1757-1768.

Garbers, D. L. 1989. Molecular basis of fertilization. Annu. Rev. Biochem. 58:719-742.

Gardner, J. P. A. 1994. The structure and dynamics of naturally occurring hybrid Mytilus edulis and $M$. galloprovincialis (Bivalvia, Mollusca) populations: review and interpretation. Arch. Hydrobiol. 99(Supp.):37-71.

1997. Hybridization in the sea. Adv. Mar. Biol. 31:1-78

Gardner, J. P. A., and D. O. F. Skibinski. 1988. Historical and sizedependant genetic variation in hybrid mussel populations. Heredity $61: 93-105$.

— 1990 . Genotype-dependant fecundity and temporal variation of spawning in hybrid mussel populations. Mar. Biol. 105: $153-162$.

__ 1991. Biological and physical factors influencing genotypedependant mortality in hybrid mussel populations. Mar. Ecol. Prog. Ser. 71:235-243.

Gardner, J. P. A., D. O. F. Skibinski, and C. D. Bajdik. 1993. Shell growth and viability differences between the marine mussel $M y$ tilus edulis, $M$. galloprovincialis and their hybrids from two sympatric populations in southwest England. Biol. Bull. 185: 405-416.

Gosling, E. M., and D. McGrath. 1990. Genetic variability in exposed-shores mussels Mytilus spp. along an environmental gradient. Mar. Biol. 104:413-418.

Gosling, E. M., and N. P. Wilkins. 1981. Ecological genetics of the mussel Mytilus edulis and $M$. galloprovicialis on Irish coasts. Mar. Ecol. Prog. Ser. 4:221-227.

Griffing, B. 1990. Use of a controlled-nutrient experiment to test heterosis hypotheses. Genetics 126:753-767.

Harrison, R. G. 1993. Hybrids and hybrid zones: historical perspective. Pp. 3-12 in R. G. Harrison, ed. Hybrid zones and the evolutionary process. Oxford Univ. Press, New York.

Hedgecock, D., D. J. Mcgoldrick, and B. L. Bayne. 1995. Hybrid 
vigor in Pacific oysters: an experimental approach using crosses among inbred lines. Aquaculture 137:285-298.

Hilbish, T. J., B. L. Bayne, and A. Day. 1994. Genetics of the physiological differentiation within the marine mussel Mytilus. Evolution 48:267-286.

Huvet, A., K. Balabaud, N. Bierne, and P. Boudry. 2001. Microsatellite analysis of 6-hour old embryos reveals no preferential fertilization between two cupped oysters Crassostrea gigas and Crassostrea angulata. Mar. Biotechnol. 3:448-453.

Lubet, P., G. Prunus, M. Masson, and D. Bucaille. 1984. Recherches expérimentales sur l'hybridation de Mytilus edulis et $M$. galloprovincialis. Bull. Soc. Zool. Fr. 109:87-99.

Palumbi, S. R. 1992. Marine speciation on a small planet. Trends Ecol. Evol. 7:114-118.

- 1994. Genetic divergence, reproductive isolation, and marine speciation. Annu. Rev. Ecol. Syst. 25:547-572.

- - 1995. Nucleic acids. II. The polymerase chain reaction. Pp. 205-247 in D. Hillis and C. Moritz, eds. Molecular systematics. Sinauer, Sunderland, MA.

. 1999. All males are not created equal: fertility differences depend on gamete recognition polymorphisms in sea urchins. Proc. Natl. Acad. Sci. USA 96:12632-12637.

Raymond, M., and F. Rousset. 1995. GENEPOP (ver. 1.2): a population genetics software for exact test and ecumenicism. J. Hered. 86:248-249.

Regier, J. C., and J. W. Shultz. 1998. Molecular phylogeny of ar- thropods and the significance of the Cambrian "explosion" for molecular systematics. Am. Zool. 38:918-928.

Skibinski, D. O. F. 1983. Natural selection in hybrid mussel populations. Pp. 283-298 in G. S. Oxford and O. Rollinson, eds. Protein polymorphism: adaptative and taxonomic significance. Systematics Association special volume no. 24. Academic Press, London.

Skibinski, D. O. F., M. Ahmad, and J. A. Beardmore. 1978. Genetic evidence of naturally occurring hybrids between Mytilus edulis and $M$. galloprovincialis. Evolution 32:354-364.

Skibinski, D. O. F., J. A. Beardmore, and T. F. Cross. 1983. Aspects of the population genetics of Mytilus (Mytilidae; Mollusca) in the British Isles. Biol. J. Linn. Soc. 19:137-183.

Sokal, R. R., and F. J. Rohlf. 1996. Biometry. 3rd ed. W. H. Freeman, New York.

Vacquier, V. D., and G. W. Moy. 1977. Isolation of bindin: the protein responsible for adhesion of sperm to sea urchin eggs. Proc. Natl. Acad. Sci. USA 74:2456-2460.

Vacquier, V. D., K. R. Carner, and C. D. Stout. 1990. Speciesspecific sequences of abalone lysin, the sperm protein that creates a hole in the egg envelope. Proc. Natl. Acad. Sci. USA 87: 5792-5796.

Ward, G. E., C. J. Brokaw, D. L. Garbers, and V. D. Vacquier. 1985. Chemotaxis of Arbacia punctulata spermatozoa to resact, a peptide from the egg jelly layer. J. Cell Biol. 101:2324-2329.

Corresponding Editor: R. Burton 